\title{
Psychosurgery: description and outcome study of a regional service
}

\author{
R. P. Snaith, E. Dove, J. Marlowe, S. Pemberton, D. J. Price, S. Rawson, J. F. \\ Wright, A. Butler, A. K. Coughlan, M. Hird and P. Trigwell
}

\begin{abstract}
The report indicates that a piychosurgery service can be established on a regional basis. The outcome study of the Yorkshire Reglonal Psychosurgery Service indicates that the treatment should retain a place in the treatment of patients who have falled to respond to other avallable approaches. For such patients (and their corers) Iffe is a state of persisting torment. Some poychiatrists consider psychosurgery as a procedure not to be countenanced, or outmoded, but patients have a right to know what may be achieved by the treatment and at what cost in ferms of possible failure to improve and adverse effects. An audit of the Regional Psychosurgery Service indicates a fovourable result of the intervention. All patients improved to some extent, some very remarkably, and no adverse effects were encountered.
\end{abstract}

There have been many reports of outcome of psychosurgical treatment for severe and intractable mental illness. Recent surveys include those of Mindus \& Jenike (1992) and Hay et al (1993). Difficulties in the interpretation of the findings arise for a number of reasons, principally: (a) definition of disorders, their duration and information of prior treatment; (b) report on only selected patients in a series; (c) lack of use of standard psychometric techniques; (d) assessment methods liable to bias or undertaken by those involved in the decisions for, and conduct of, the treatment; (e) lack of information on aftercare following discharge from the psychosurgical unit and, (f) variable standards of postoperative rehabilitation or information on subsequent care.

No outcome report is free of all these criticisms and many contain most of them. A further problem arises from the variety of surgical techniques used, placing different lesions by different methods.

The report of outcome of psychosurgery, if it is to be a guide to others considering this intervention, must be undertaken with as much attention as possible to the above points. For this reason we present the audit of a consecutive series of patients who underwent psychosurgery at the Yorkshire Regional Psychosurgery Service over a 10 year period. The procedure of this Service has been described elsewhere (Snaith et al, 1984) but the essential points are:

(1) The referring psychiatrist provides detailed clinical information of the nature of the disorder and all treatments so far undertaken.

(2) The Service Director decides, on the basis of the information and discussion with the referring psychiatrist, whether a case conference should be held or whether to defer this pending further treatment or investigation. The state of physical health must be assessed since the period under anaesthesia (which includes the fitting of the stereotactic frame) is long. Brain imaging is an essential preliminary investigation.

(3) If the referral appears suitable the referring psychiatrist then informs the patient and relatives that a case conference for the purpose of considering the possible role of psychosurgery in further treatment may be held and ensure that the patient would consent to psychosurgery were it to be considered likely to alleviate the distress of the disorder. The patient is advised that frequently no decision to proceed to psychosurgery is made at the case conference which is for the purpose of assembling all relevant information and (if psychosurgery appears likely to be beneficial) providing information of the procedure, likelihood of relief and unwanted effects of the procedure. It is necessary to consider, at this stage, which members of the care team would be the staff identified for the interrogation by the Mental Health Commission should psychosurgery be advised. If psychosurgery is to be considered, any further therapeutic procedures prior to this intervention are discussed and a date for a 
second case conference, some three months later, arranged.

(4) If psychosurgery is advised, the referring psychiatrist makes arrangements with the Mental Health Commission for the visit required for approval under the relevant Section of the Act (Section 57).

(5) Following approval, the patient is admitted to the psychiatric unit for familiarisation with the staff who will be conducting the post-surgical rehabilitation procedures. The patient (and relatives) are informed that a short period of post-operative confusion is to be expected but clears within a week or two and does not signify an adverse outcome. Transfer to the neurosurgical unit follows and surgery is conducted. Using stereotactic procedure, bilateral lesions, one centimetre in coronal length, are made by suction in the radiation of neurons from the pre-frontal cortex to the hypothalamus (the infero-medial position) ${ }^{1}$. Following recovery an anticonvulsant drug is prescribed for six months.

(6) On return to the psychiatric unit, rehabilitative procedures are energetically undertaken in the period of 3 months before the patient returns to the care team; these

include as much social and occupational guidance and activity as possible. During this period careful assessments are made concerning requirement for further psychotropic medication. In the case of patients suffering from obsessional disorders, further cognitive and behavioural measures are usually necessary.

(7) On return to the care of the referring team any further treatment measures are discussed. Expectation of further gradual improvement is reasonable so long as attempts to resume normal life activities are maintained.

\section{The survey}

During the 10-year period of this survey, 12 referrals were made to the Regional Psychosurgery Service. This led to a case conference in 10 cases. Seven patients were recommended for, and underwent, psychosurgery and the outcome was assessed as follows: all patients in the survey had undergone psychosurgery at least one year before

'The videotape demonstration is avallable from: $P$. Wiehl, Media Resource Officer, Postgraduate Medical Centre, Pinderfields Hospitals Trust. Aberford Road, Wakefield WF1 4DG (for further details telephone: 01924212517 ). the assessments were made. All patients had undergone the 2-3 month post-operative, inpatient rehabilitation which is a feature of the intervention by the Service. The salient clinical details (ICD-10 codes in brackets) of the patients were:

VH, female. Severe Depressive Disorder (32.2), commencing at age 27 years. No sustained periods of improvement for 22 years. Overwhelming anxiety attacks leading to episodes of screaming. Age 66 at psychosurgery.

MW, female. Recurrent Depressive Disorder (33.2), commencing at age 28 years. Episodes becoming increasingly prolonged and resistant to treatment. Age 39 at psychosurgery.

$\mathrm{SD}$, female. Obsesstve-Compulsive Disorder, predominant ruminations (42.0), commencing at 14 years. Increasingly severe depression with suicidal attempts. Age 50 at psychosurgery.

Ch M, female. Obsessive-Compulsive Disorder, predominant ruminations (42.1), commencing at 9 years. Severe anxiety. Age 40 at psychosurgery.

DT, male. Obsesstve-Compulsive Disorder. mixed ruminations and rituals (42.2) with schizotypal personality disorder, commencing at 23 years. Age 46 at psychosurgery.

AT, female. Obsessive-Compulsive Disorder, predominant rituals (42.1), commencing at 15 years. Aged 21 at psychosurgery.

AM, male. Obsessive-Compulsive Disorder, predominant ruminations (42.1), commencing at 20 years. Predominant phobla concerning his harming children. Age 41 at psychosurgery.

\section{Assessment procedure}

\section{The pre-surgical assessments}

(1) Global Assessment of Function-GAF (DSM-III-R; American Psychiatric Association, 1987) providing an overall measure of disablement.

(2) Comprehenstve Psychiatric Rating Scale (CPRS; Asberg et al, 1978), which is an assessor-rated instrument from which three subscales were extracted: (a) anxiety (items: worry, tension, anxious appearance and restlessness); (b) depression (items: sadness, loss of emotional reactivity, depressed appearance and hopelessness); (c) obsessional psychopathology (items: ritualistic behaviour and ruminative thoughts).

(3) The Hospital Anxiety and Depression Scale (HADS; Zigmond \& Snaith, 1984), a selfassessment scale providing separate measures of anxiety and depression.

Ratings on the first two of these instruments were made jointly by RPS and the trainee 
psychiatrist to the psychosurgery team during the week prior to surgery.

\section{Post-psychosurgery assessments}

Assessments were conducted independently for each patient by four mental health workers each experienced in conducting assessments in their particular field. None of the assessors had played any part in previous assessments nor had any role in the assessment procedures leading to the decision to conduct the psychosurgery. The auditors were a senior lecturer in mental health social work, a consultant clinical psychologist, a community psychiatric nurse and a psychiatric registrar. They were not informed of pre-psychosurgical data and were instructed not to discuss their assessments with each other.

The assessments by the sociologist, the nurse and the psychiatrist all included a rating on the Global Assessment Scale and the second and third of these assessors obtained a HADS rating. The psychiatric assessor conducted the CPRS rating procedure. The clinical psychologist conducted a battery of psychometric tests. The sociologist and the community nurse conducted their assessments in the homes of the patients, but patients were seen at St James's University Hospital for the assessments by the psychologist and the psychiatrist.

\section{Findings}

\section{Psychometric testing ${ }^{2}$}

This aimed to provide a fairly wide range of indices of intellectual functioning. Some presurgery cognitive test data were available for six of the seven patients but this was of limited use because outdated versions of tests had been used in some instances and because of uncertainty about the effects of the patients' psychiatric disorder on their test performances.

Intellectual assessment was carried out on all patients using a short form (eight subtests) of the Wechsler Adult Intelligence Scale-Revised (WAIS-R: Wechsler, 1986) and the resulting full scale IQs compared with estimates of the premorbid full scale IQs derived from the National Adult Reading Test (NART; Nelson \& Willison, 1991) scores. Two patients, AM and ChM, displayed IQ levels significantly below the predicted levels but comparison with such presurgery IQ data as were available did not indicate decline following surgery.

${ }^{2}$ Full information on psychometric tests, their results and their references available on request (send A4 stamped addressed envelope to RPS).
Six of the seven patients were assessed on a further battery of tests of cognitive abilities but this was inappropriate for the seventh patient. $\mathrm{VH}$, in view of her age. Interpretation of test results was made in the light of the patients' academic and occupational histories and their NART scores. Memory was assessed with tests of list learning and design learning (Coughlan \& Hollows, 1985), word recognition and face recognition (Warrington, 1984). Performance was mostly around the average level, 1.e. without obvious impairment, but two patients (again ChM and AM) displayed instances of very poor performance - AM on three of the four tasks and ChM on one of the tasks; both patients had displayed some evidence of memory impairment during pre-surgery assessment. Word retrieval was assessed by a task of naming pictures of objects (Warrington, 1984) and there was no reason to suspect impairment, abilities ranging from below average to average. Speed of information processing was assessed using the Stroop test (Trenerry et al, 1989) and the Trail Making test (norms by Davies, 1968). The patient AM displayed weak performance (below the 10th percentile) on both these tests and ChM and SD did so on the Trail Making test. Performance on tests of 'frontal lobe' cognitive functioning, i.e. Cognitive Estimations (Shallice \& Evans, 1978) and Word Fluency, using letters C, F and L (Benton \& Hamsher, 1978), revealed no evidence of impairment: scores on Cognitive Estimations were all within the normal range and scores on Word Fluency were average or better. Two of the patients, AM and DT, displayed abnormally high scores on the State measure of the State-Trait Inventory (Spielberger, 1983).

Thus, of the seven patients, five appeared to display intact, or very nearly intact, performance on cognitive tests and two displayed impairment. most noticeably on tests of general intellect and memory.

The outcome of the assessments by the sociologist, the nurse and the psychiatrist are presented in Fig. 1 in which the GAF rating is the mean of the three individual ratings (none of which varied from each other by more than 10 points). The table in Fig. 1 indicates the degree of improvement or worsening in terms of change of state: the HADS provides four categories of severity for both anxiety and depression: normal (1), mild (2), moderate (3) and severe (4). Thus a change from a pre-psychosurgery severe to a normal rating would be indicated by +3 and the reverse would be -3 . For the CPRS the anxiety and the depression subscale scores were derived by summation of the ratings on the items. Thus the maximum score for each subscale was 12 points and for both the range of change score was from +12 to -12 . Since the scale for obsessional psychopathology was composed of just two items 


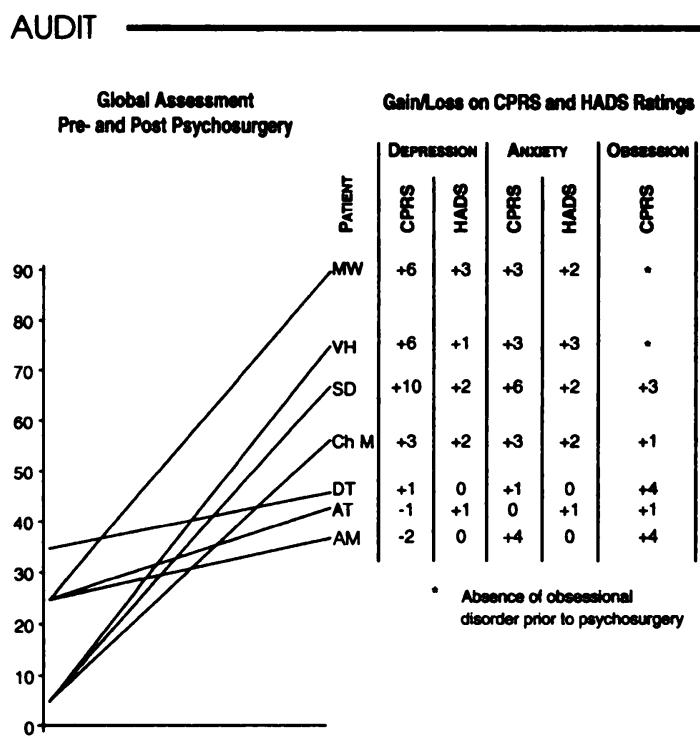

Figure 1. Outcome information on psychometric tests.

the change range was from +6 to -6 . The outcome information on these tests is represented in Figure 1.

\section{Reports from patients' psychiatrists}

The psychiatrists who had referred the patients for psychosurgery were asked to complete a visual analogue line scale, anchoring statements "Psychosurgery did not help the patient at all" to "Psychosurgery relieved the patient of all distress of the mental illness". They were also invited to add their comment in writing. The results of this exercise were:

MW: $100 \%$ improvement: "The result of the treatment has been quite extraordinary and surpassed any view I had as to the degree of improvement that could be obtained".

SD: $100 \%$ improvement: "There has been a very good result".

VH: 75\% improvement: "From being a pathetic, tortured, chronically hospitalised patient she is now in her home and picking up some social activities, much to her husband's delight".

AM: $60 \%$ improvement. "He was persistently in hospital but now has limited contact with the psychiatric service; he is probably drinking heavily".

DT: $10 \%$ improvement. "He is slightly more settled but very obsessed with sex and fear of losing control although he does say that he does not have to retrace his steps as much as he used to. I think the improvement following psychosurgery is very modest".

AT: $40 \%$ improvement. "She at least now attends a day centre whereas previously she could not leave her room on account of her fear of contamination".

ChM: $60 \%$ improvement. "Much of the overwhelming anxiety concerning ruminations about disease and sexual themes has diminished to the point where she is little troubled; but she still becomes depressed and requires antidepressant drugs".

\section{Comment}

The results indicate that a satisfactory psychosurgical service may be organised on a regional basis and that there are advantages to this. It also indicates that psychosurgery retains a role in the management of some severe obsessional and anxiety/depressive state which have not improved with other available treatments. All the patients had long, exhausting histories of psychiatric disorders. Psychiatric workers as well as the patients were at the ends of their tether in all cases.

In three of the seven patients the improvement was very great and no patient regretted having undergone the treatment. The amount of postpsychosurgery treatment time was considerably reduced. There were no adverse neurological sequelae and in all cases anticonvulsant drugs were stopped within six months without occurrence of fits.

Psychometric testing revealed no convincing evidence that psychosurgery resulted in cognitive impairment. Moreover the CPRS ratings showed no evidence of disorientation or dysmnesia.

It seems probable that the surgical method used produces results as good as those in which more extensive lesions are made. The outcome of this audit does not lead us to consider that we should change the approach although we accept there is a possibility of a better outcome by some other operation. A recent review (Baer et al, 1995) of outcome of a large number of patients suffering from obsessional disorder and who had undergone cingulotomy surgery, revealed a $45 \%$ improvement which does not indicate a superior outcome than with the lower medial quadrant siting of lesion we have retained. The study by Mindus \& Jenike (1992), provides a useful outcome survey by different surgical approaches and no method was clearly superior. We would stress the importance of good post-surgical rehabilitation with careful attention to any necessary psychiatric treatment procedures.

Rappaport (1992) provides a comment on the 'ethical' aspects of psychosurgery and of the past causes for professional and societal unease with psychosurgery and concludes that, with proper supervision, "it is appropriate to consider the use of psychosurgery in well-defined clinical entities 
of mental disease which do not respond to alternative therapy."

\section{References}

AMERICan Psychiatric Association (1987) Diagnostic and Statistical Manual of Mental Disorders (3rd edn revised) (DSM-III-R). Washington. DC: APA.

Ásberg, M. Montgomery, S. A. Perris, C., et al (1978) A Comprehenstve Psychopathological Rating Scale (CPRS). Acta Psychiatrica Scandinavica. Suppl. 271, 5-9.

BAER, L. RAuCH, S. L., BaLlantine, T., et al (1995) Cingulotomy for intractable obsesstve-compulstive disorder. Archives of General Psychiatry, 62, 384-392.

BENTON, A. L. \& HAMSHER, K. de S. (1978) The Multilingual Aphasia Examination (Revised Manual). Iowa City: Untversity of lowa.

Coughlan, A. K. \& Howows, S. E. (1985) The Adult Memory and Information Processing Battery. A. K. Coughlan: Leeds.

DAVIES. A. (1968) The influence of age on Trail Making test performance. Joumal of Clinical Psychology, 24, 96-98.

HaY, P. SACHDEv, P., CUMming. S., et al (1993) Treatment of obsesstve-compulstve disorder by psychosurgery. Acta Psychiatrica Scandinavica, 87, 197-207.

MindUS. P. \& JENIKE, M. A. (1992) Neurosurgical treatment of malignant obsesstve-compulsive disorder. Psychiatric Clinics of North America, 16, 921-938.

Nelson, H. E. \& Wiuson, J. R. (1991) The National Adult Reading Test: Part II. Windsor: NFER-Nelson Publishing.

RAPPAPORT, Z. H. (1992) Psychosurgery in the modern era: therapeutic and ethical aspects. Medicine and Law, 11 $449-453$.

Shaluce, T. \& Evans, M. (1978) The involvement of the frontal lobes in cognittive estimation. Cortex, 14, 294 303.

SNATH, R. P., PRICE, D. J. E. \& WRIGHT, J. F. (1984) Psychiatrists' attitudes to psychosurgery. Brittsh Joumal of Psychiatry. 144. 293-298.

SPIELBERGER, C. D. (1983) Manual for the State-Trait Andety Inventory STAI (Form Y). California: Consulting Psychologists Press.
TrEnERRY, M. R., Crosson, B., Deboe, J., et al (1989) Stroop Neuropsychological Screening Test. Odessa. Florida: Psychological Assessment Resources Inc.

WARRINGTON, E. K. (1984) Recognitton Memory Test. Windsor: NFER-Nelson Publishing.

WECHSLER, D. (1986) The Wechsler Adult Intelligence Scale Revised: UK Edition. Sidcup: The Psychological Corporation Ltd.

ZigmOND, A. \& SNATT, R. P. (1984) The Hospital Andety and Depression Scale. Windsor NFER-Nelson Publishing.

\section{Psychosurgery Service Team}

-R. P. Snaith, Senior Lecturer and Honorary Consultant Psychiatrist, St James's University Hospital, Leeds LS9 TTF; E. Dove, Nurse specialist (psychosurgery); J. Marlow, Charge Nurse; S. Pemberton, Principal Occupational Therapist, Leeds Community and Mental Health Services; D. J. E. Price, Consultant Neurosurgeon, Pinderfields Hospital, Wakefield; S. Rawson, Principal Psychiatric Social Worker; and J. F. Wright, Consultant Clinical Psychologist, Leeds Community and Mental Health Services.

\section{Specialist Assessors}

A. Butler, Senior Lecturer in Mental Health Social Work, University of Leeds; A. K. Coughlan, Consultant Clinical Psychologist, St James's and Seacroft Trust, Leeds; M. Hird, Community Psychiatric Nurse; and P. Trigwell, Senior Registrar, Leeds Regional Training Scheme, Leeds Community and Mental Health Services.

*Correspondence 